\title{
Epidermodysplasia verruciformis: An early and unusual presentation
}

\author{
Ilteris Murat Emsen MD PhD ${ }^{1}, M$ Esref Kabalar MD ${ }^{2}$
}

\begin{abstract}
IM Emsen, ME Kabalar. Epidermodysplasia verruciformis: An early and unusual presentation. Can J Plast Surg 2010;18(1):21-24.

Epidermodysplasia verruciformis is a rare, heritable disease characterized by an unusual susceptibility to infection with specific types of human papillomavirus and a propensity for developing malignant skin tumours. Partial defects in cell-mediated immunity have been demonstrated in this disease. In the present report, a young patient with epidermodysplasia verruciformis who was treated successfully with surgical treatment is described.
\end{abstract}

Key Words: Cell-mediated immunity; Epidermodysplasia verruciformis; Human papillomavirus

C pidermodysplasia verruciformis $(\mathrm{EV})$ is a rare, lifelong, cutaEneous, autosomal recessive genetic disorder of the immune system manifested by increased susceptibility to cutaneous human papillomavirus (HPV) infection beginning in the early years of life. This disorder was first described by Lewandowsky and Lutz (1) in 1922 as an epidermal nevus. In 1939, Sullivan and Ellis (2) described a close relationship between EV and high risk of skin cancer. In EV, there are mutations in the EVER1 or EVER2 genes on chromosome 17q25, which, due to a defect of cell-mediated immunity, lead to an abnormal susceptibility of the patients to a specific group of HPV genotypes known as EV HPV. Most of these are HPV 5 and 8; more rarely, HPV 14,17, 20 and 47, and all have oncogenic potential (3).

The clinical diagnostic features are lifelong eruption of pityriasis versicolor-like macules and flat, wart-like papules, which are associated with a high risk of nonmelanotic skin cancer on sun-exposed areas. The initial lesions often occur in childhood. Other benign cutaneous lesions are macules and seborrheic keratosis-like plaques. These lesions characteristically present with malignant transformation in $35 \%$ to $50 \%$ of

\section{L'épidermodysplasie verruciforme : Une présentation précoce et inhabituelle}

L'épidermodysplasie verruciforme est une maladie congénitale rare caractérisée par une susceptibilité inhabituelle à l'infection par des types précis de papillomavirus humains et une propension à développer des tumeurs cutanées malignes. Des anomalies partielles de l'immunité à médiation cellulaire sont démontrées dans cette maladie. Dans le présent rapport, on décrit le cas d'une jeune patiente atteinte d'épidermodysplasie verruciforme dont le traitement chirurgical a réussi.

patients, especially those 40 to 50 years of age with Bowen's-type carcinoma in situ being the most frequent tumour, followed by invasive squamous cell carcinoma; however, metastasis is rarely encountered. Similar cutaneous lesions can be seen in other immunocompromised conditions and procedures, such as AIDS and allograft organ transplantation (4).

We report the case of a young patient with a history of EV who presented with squamous cell carcinoma that developed over a short period of time. The patient was succesfully treated with surgical reconstruction.

\section{CASE PRESENTATION}

A 14-year-old girl was referred to the plastic surgery department by a dermatologist who had biopsied a lesion on the infraorbital region that subsequently was determined to be squamous cell carcinoma. Her medical history included a progressive appearance of widespread asymptomatic lesions since six years of age. She had three sisters and three brothers, and one sister had similar lesions. Four years previously, the patient was diagnosed with EV based on biopsies taken from lesions on her back (Figure 1). One year after
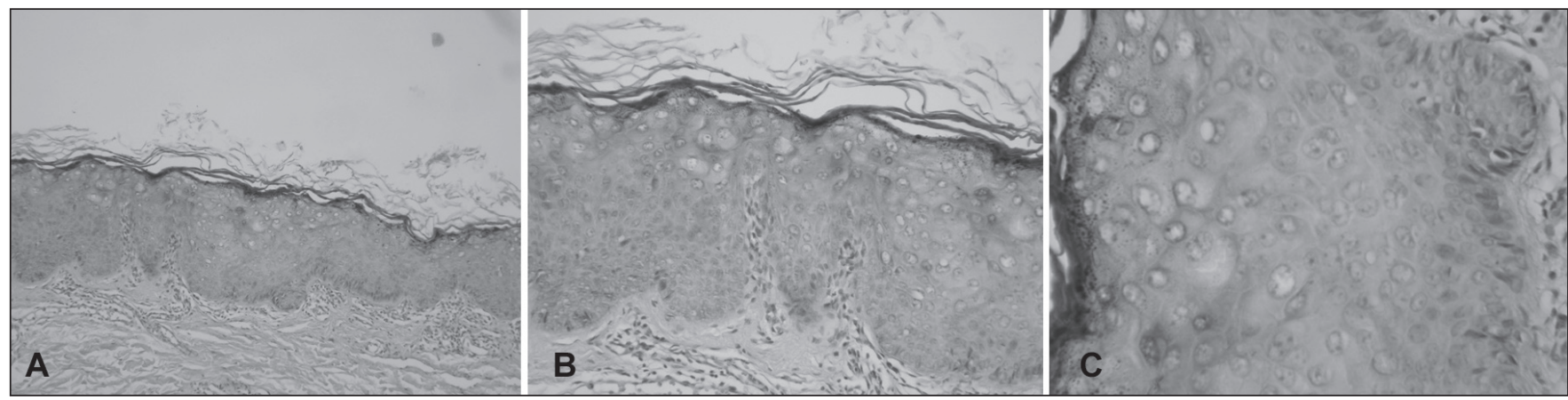

Figure 1) Histological sections of the lesion showing a hyperkeratotic and slightly acanthotic epidermis. Vacuola cells are present in the upper stratum malpighii and granula layer (hematoxylin and eosin stain, original magnification $\times 100$ [A]; hematoxylin and eosin stain, original magnification $\times 200[\mathbf{B}]$; hematoxylin and eosin stain, original magnification $\times 400$ [C])

${ }^{1}$ Department of Plastic Reconstructive and Aesthetic Surgery; ${ }^{2}$ Department of Pathology, Numune State Hospital, Erzurum, Turkey

Correspondence: Dr Ilteris Murat Emsen, Ataturk Universitesi Lojmanlari, 4.Blok, No 30, 25240 Erzurum, Turkey.

Telephone 904-422-360-722, fax 904-422-321-031, e-mail ilterisemsen@hotmail.com 


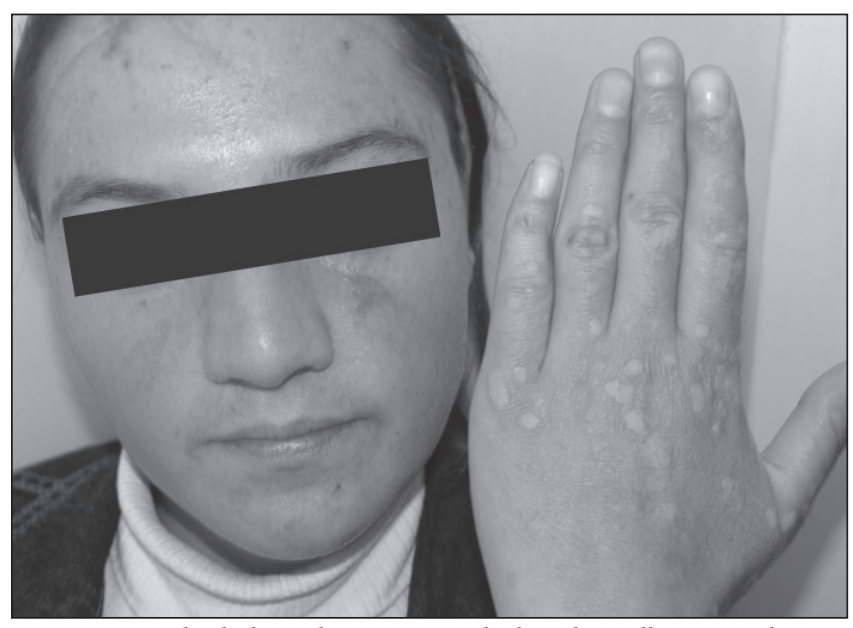

Figure 2) Multiple hyperkeratotic, pinkish-red papillomatous lesions and tan-coloured macular lesions on her hands

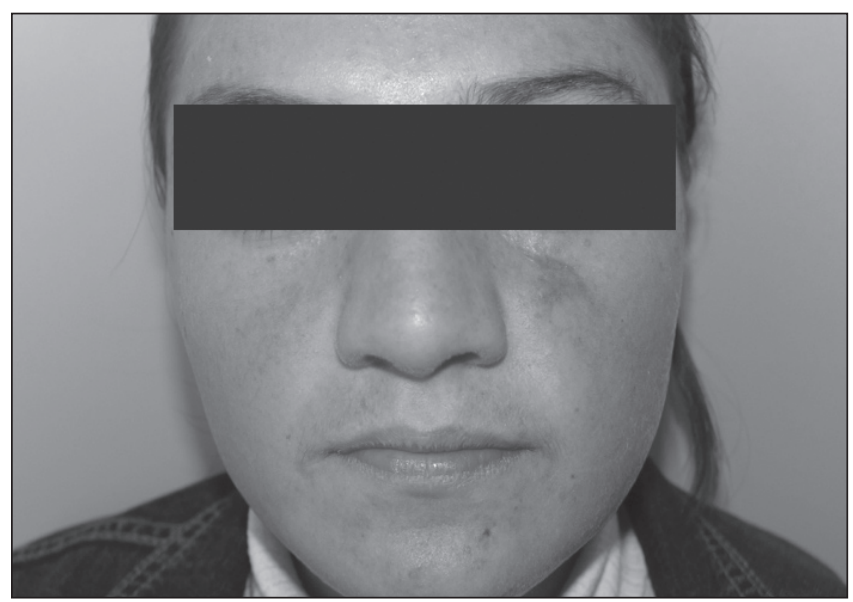

Figure 3) Preoperative frontal view of the scarred mass

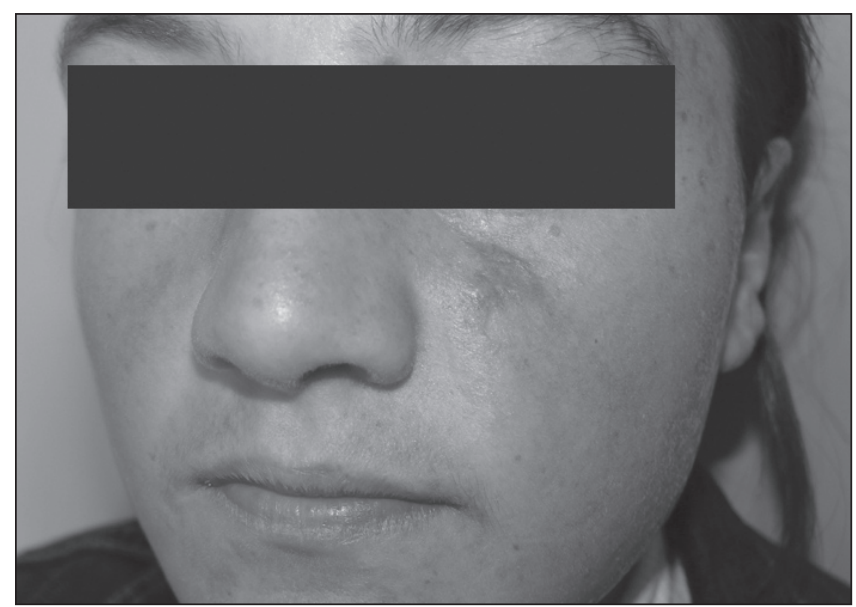

Figure 4) Preoperative lateral view of the mass

the biopsy, an excisional biopsy was performed on a nonhealing lesion on her left infraorbital region. The pathological examination revealed squamous cell carcinoma, and the patient was referred to the plastic surgery department.

Physical examination revealed multiple hyperkeratotic, pinkish-red macular and particularly papillomatous lesions on both extremities - hands and back (Figure 2). There was a

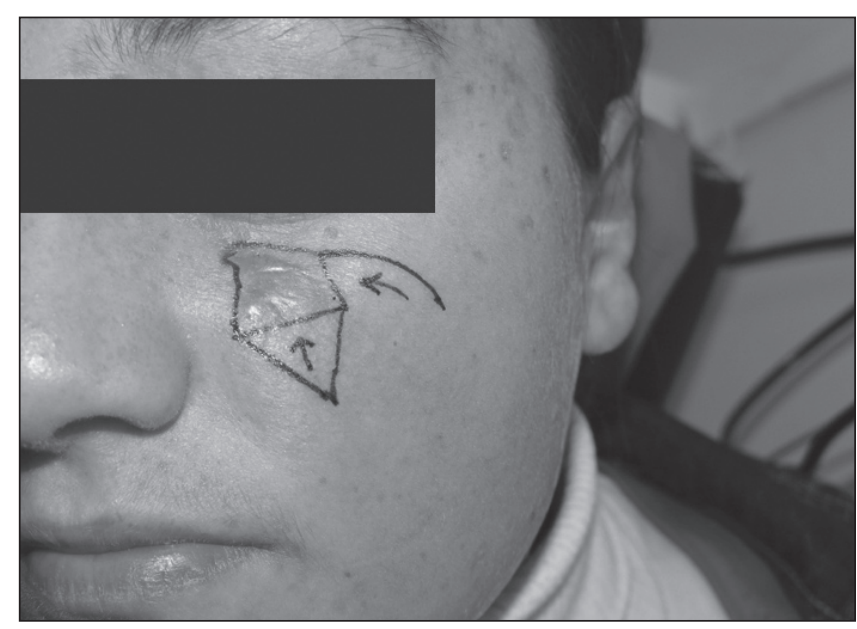

Figure 5) Preoperative design of the V-Y and Mustarde flaps

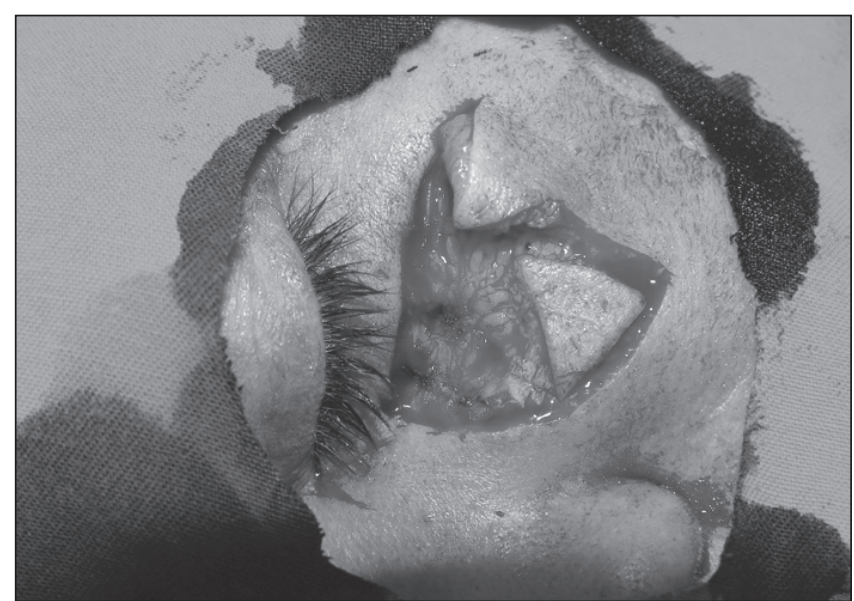

Figure 6) Perioperative view of the prepared flaps and after removed mass

pinkish scarred lesion on the left infraorbital region that measured approximately $2 \mathrm{~cm} \times 2.5 \mathrm{~cm}$ in size (Figures 3 and 4).

On the laboratory examination, her complete blood cell counts and biochemical blood parameters, hematological bleeding parameters, hepatitis, rheumatology markers and HIV markers were all normal. The systemic tumour markers were also within normal ranges.

The old infraorbital scarred mass was excised and the defect was reconstructed with a combination of a modified Mustarde technique and V-Y advancement flaps (Figures 5 and 6 ). The postoperative pathological examination revealed squamous cell carcinoma. The patient has remained healthy for 14 months postoperatively, and during this period, she received interferon therapy. No additional mass has appeared to date (Figures 7 and 8).

\section{DISCUSSION}

EV is usually suspected with the appearance of generalized wart-like lesions early in life, and histological examination of the lesions, immunological status of the patient and detection of HPV DNA in the lesions. Genetic factors are suspected to cause EV; prolonged exposure to sunlight precipitates malignant degeneration of the lesion. The infection manifests with the appearance of benign, planar, wart-like and pityriasis 


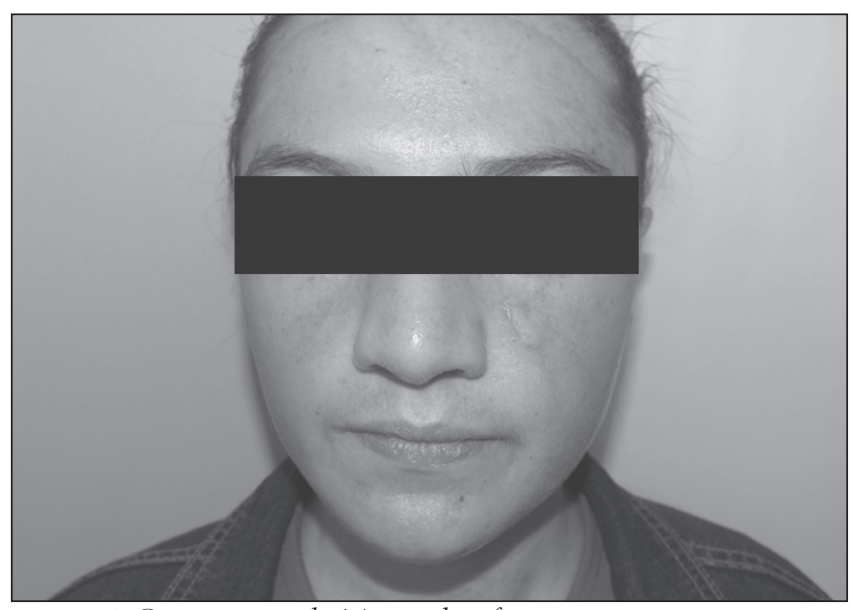

Figure 7) Cosmetic result 14 months after surgery

versicolor-like macules at childhood. Only skin is involved. Historically, malignant conversion (ie, actinic keratosis, Bowen's disease and squamous cell carcinoma) in EV required at least 20 to 30 years. However, nowadays, malignant conversion is seen over shorter periods of time, possibly due to the increase of time to sun exposure, altitude or outdoor occupations (5). Therefore, malignancies start to appear well before 40 years of age. The lesions appear mainly on sun-exposed areas, frequently on the forehead. This could be explained by the combination of chronic ultraviolet exposure and probable presence of oncogenic EV-HPV in hair follicles. Ultraviolet and $\mathrm{x}$-rays are cocarcinogens. Metastasis in these cases is very rare if there is no history of radiation therapy (6).

Sun exposure can greatly hasten time to malignant transformation. If a patient with EV is living at a high altitude and/or works outdoors and does not use sunscreen, malignant transformation can be seen earlier in the disease progression.

\section{Nonsurgical treatment}

\section{TREATMENT}

Several nonsurgical treatment modalities have been tried for $\mathrm{EV}$, including oral and topical retinoids, interferon, immunotherapy, electrodesiccation and cryotherapy. However, all of these treatments have either been ineffective or have had temporary results. These lesions generally require surgical excision and reconstruction of the defects. This seems to be the most effective treatment and the only way to increase survival. Pharmacological treatment may improve quality of life for affected individuals (7).

Oral retinoids have been used in early premalignant lesions. These have an antiproliferative and differentiationinducing effect that is believed to prevent the occurrence of malignant lesions. However, their antimalignant effects have not yet been documented. Oral retinoids do not eradicate HPV infections, and serious side effects have been observed with clinical use.

Another proposed agent is interferon; however, the patient must have an intact immune system for clinical benefit. Imiquimod, another therapeutic agent, induces the production of cytokines from monocytes and macrophages, thus stimulating the $\mathrm{T}$ cell helper 1 response and most probably the cytotoxic T cell activation and B cell response (8). Two cases

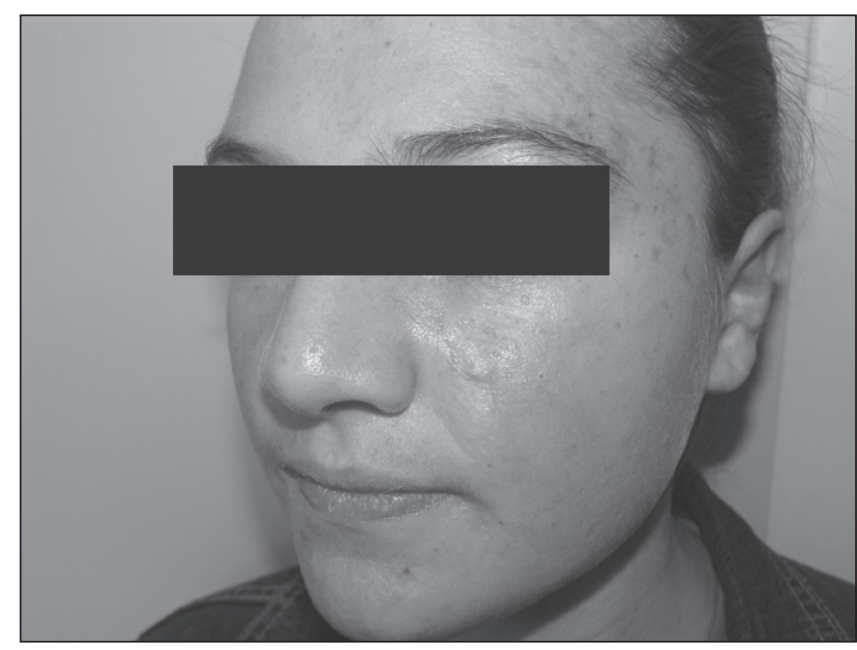

Figure 8) Closer view after surgery

have been published on this agent. Hu et al (9) found imiquimod to be ineffective in two HIV-positive maternal half brothers with EV. However, Berthelot et al (10) found imiquimod to be an effective treatment for EV. Due to these conflicting outcomes, imiquimod should be studied further before using for this indication. Another agent, cimetidine, depresses mitogen-induced lymphocyte proliferation and suppressor $\mathrm{T}$ cell activity features. Oliveira et al (11) found that cimetidine was not effective in the treatment of EV.

\section{Surgical treatment}

Although more radical than pharmacological treatment, surgical treatment is considerably more effective. Complete excision and defect reconstruction with split-thickness or full-thickness skin grafts or local flaps are the preferred approaches.

\section{CONCLUSION}

Extended exposure to sunlight, outdoor occupations, not using sunscreens and living at high altitudes all precipitate malignant degeneration of EV lesions. Our patient lived on a farm, and had been working outside with her father and other family members. The farm was located $1800 \mathrm{~m}$ above sea level. She had never used sunscreens because she did not know about them. As a result, she developed skin malignancy well before the usual time course of this disease.

CONFLICTS OF INTEREST: The authors have no conflicts of interest to declare.

\section{REFERENCES}

1. Lewandowsky F, Lutz W. Ein Fall einer bisher nicht beschriebenen Hauterkrankungn (Epidermodysplasia verruciformis). Arch Dermatol Syphilol 1922;12:306-16.

2. Sullivan M, Ellis FA. Epidermodysplasia verruciformis

(Lewandowsky and Lutz). Arch Derm Syph 1939;40:422-32.

3. Ramoz N, Taieb A, Rueda L, et al. Evidence for a nonallelic heterogeneity of epidermodysplasia verruciformis with two susceptibility loci mapped to chromosome regions 2p21-p24 and 17q25. J Invest Dermatol 2000;114:1148-53.

4. Bogdan I, Secharer L, Rüdlinger R, et al. Epidermodysplasia verruciformis in two brothers developing aggressive squamous cell carcinoma. Dermatol Surg 2007;33:1525-8.

5. Segura S, Carrera C, Ferrando J, et al. Dermascopy in epidermodisplasia verruciformis. Dermatol Surg 2006;32:103-6. 
6. Majewski S, Jablonska S. Epidermodysplasia verruciformis of a model of human papillomavirus-induced genetic cancer of the skin. Arch Dermatol 1995;131:1312-8.

7. Ortak T, Uysal AC, Alagoz MS, Orbay H, Sensoz O.

Epidermodysplasia verruciformis: An unusual presentation.

Dermatol Surg 2006;32:302-6.

8. Anadolu R, Oskay T, Erdem C, Boyvat A, Terzi E, Gürgey E.

Treatment of epidermodysplasia verruciformis with a combination of acitretin and interferon alfa- 2a. J Am Acad Dermatol 2001;45:296-9.
9. Hu W, Nuovo G, Willen M, Somach S. Epidermodysplasia verruciformis in two half brothers with HIV infection. J Cutan Med Surg 2004:8:357-60.

10. Berthelot C, Dickerson M, Rady P, et al. Treatment of a patient with epidermodysplasia verruciformis carrying a novel EVER2 mutation with imiquimod. J Am Acad Dermatol 2007;56:882-6.

11. Oliveira WR, Neto CF, Rivitti EA. The lack of a clinical effect of cimetidine in the treatment of epidermodysplasia verruciformis. J Am Acad Dermatol 2004;50:e14. 